\title{
Connection and Disconnection of Research and Practice in the Education of Professional Psychologists
}

\author{
Donald R. Peterson Rutgers University
}

Education for the practice of psychology has evolved through a preprofessional phase, a scientist-professional phase, and a professional phase, in which each successive pattern of education complements but does not replace the prior pattern. Each phase of development is grounded in its own assumptions about relations between research and practice. The concepts of practice as applied science, reciprocity of science and profession, and practice as disciplined inquiry are considered. The concept of practice as disciplined inquiry is appropriate to the education of professional psychologists. Complementarity of basic research, applied research, and professional service requires appreciation of fundamental differences as well as similarities in the structure of research and practice.

Among all the misunderstandings that contaminate rational discussion about the education of professional psychologists, none is more fundamental nor more difficult to dislodge than the idea that the direct education of professionals entails a rejection of research. No one I respect has ever suggested that. I never have. My central claim is that scientific research and professional service are different in important ways, and that different forms of education are required to prepare people for careers of research, in the one case, or careers of professional service, in the other case. Combinations are possible, but rarely fit the dispositions of students or the demands of employment following graduate education.

Because I have been writing and speaking on this topic for more than 25 years and still hear otherwise sane and literate people ask me why I am opposed to science, I hold no illusion that my remarks will put the confusion to its final rest. All I intend in the following statement is to approach the issue of relations between research and practice from a somewhat different direction than I have taken before and hope that my comments will be constructive.

First I will offer a brief review of the history of education for the practice of psychology, within which three clear phases can be marked. Then I will examine assumptions about relations between the science and the profession that have predominated in each phase, and conclude with the recommendation that basic scientists, applied researchers, and professional psychologists pursue their distinct but related missions in complementary and cooperative ways.

\section{History of Education for the Practice of Psychology}

\section{Preprofessional Phase}

From the beginning, the American expression of psychology has contained a strong utilitarian component. More than our European counterparts, we have asked what uses can be made of knowledge about human function. The first psychological clinics were formed in the United States. Psychological tests were originally devised in Britain and France, but the testing movement and assessment more generally have been predominantly American inventions. The first time-and-motion studies in industry were done by American psychologists. The first studies of worker morale were done here. Psychoanalysis as a profession took root more firmly and grew more profusely in America than in Europe. Throughout our history, in the schools, in mental health settings, in the military, in the workplace, American psychologists have pressed the applications of psychology as far as they will go.

As intrepid as American psychologists have been in forging ahead with applications, however, they have avoided the issues of education for practice with a phobic caution. For the first 65 years of our history, psychologists entered careers of practice with no systematic preparation for professional work. They were educated as scientists. The people who created psychology, of course, came from other fields. Freud was a physician. Pavlov was an experimental physiologist. William James was educated as a physician, and his heart was in philosophy. As professorships and then departments of psychology were established, people who entered the field learned whatever their teachers had to tell them. Students who went to Cornell and studied with E. B. Titchener learned structural psychology and the introspective method. Students who went

Editor's note. Articles based on APA award addresses that appear in the American Psychologist are scholarly articles by distinguished contributors to the field. As such, they are given special consideration in the American Psychologist's editorial selection process.

This article was originally presented as a Distinguished Education and Training Contributions award address at the 98th Annual Convention of the American Psychological Association in Boston in August 1990.

Author's note. Correspondence concerning this article should be addressed to Donald R. Peterson, Graduate School of Applied and Professional Psychology, Rutgers University, Busch Campus, P.O. Box 819, Piscataway, NJ 08855-0819. 
to Harvard and studied with William James learned a dynamic functionalism. Whatever the content, however, and no matter who taught them, what they learned was scientific psychology as their professors defined it. Aside from demonstrations in the clinics of the day, such clerkships and practica as their advisors might arrange, and the limited internships that were sometimes tacked onto the academic courses and dissertation required for the $\mathrm{PhD}$ degree, no systematic preparation for practice was available. When psychologists entered professional careers, as they did in increasing numbers after World War I, they had to figure out what to do by trial and error, or if they were fortunate, as apprentices to a mentor who had walked the path before them. In the development of education for the practice of psychology, it is fair to call the first two thirds of our 100-year history a preprofessional phase.

\section{Scientist-Practitioner Phase}

All this changed after World War II. As Americans faced the return of 16 million veterans and perhaps 100,000 psychiatric casualties, the need for psychiatrists, social workers, and clinical psychologists to help our military heroes return to civilian life was widely recognized, and use of public funds to train them found immediate political sympathy. Through the Veterans Administration (VA) and the National Institute of Mental Health (NIMH), the federal government supported the development of programs in clinical and counseling psychology. Like all federal grants, those from the VA and NIMH imposed conditions of accountability. The institutional setting of every funded program had to be stable and supportive. Curricular content had to be specified. A system for program accreditation had to be established. With large financial incentives in sight, academicians somehow overcame the ambivalence that had impeded previous efforts to define the education of professional psychologists. In the report of the Shakow Committee (American Psychological Association [APA], 1947) and then at the Boulder Conference (Raimy, 1950), the basic conditions for educating professional psychologists were set. The institutions in charge were academic departments. The model of training was that of the scientist-practitioner. The APA would assume responsibility for accrediting programs. With clear definition of an educational philosophy and a bounding growth of clinical programs all across the country, we entered the scientist-practitioner phase of development in education for practice in our field.

Before I say another word, I need to make clear that I am not unsympathetic to the Boulder model of education in psychology. In its modesty, the scientist-practitioner concept has enormous power. It acknowledges that the conceptual, methodological, and substantive bases for the practice of psychology forever need improving, and that an unending flow of sound research is required to bring that improvement about. I believe our research universities should continue to nurture strong research- oriented scientist-practitioner programs. I believe we should exploit every opportunity to link practice and research as Barlow, Hayes, and Nelson (1984), Stricker and Keisner (1985), and many others have proposed. I applaud the work of the recent Gainesville Conference in reaffirming the values of the scientist-practitioner concept and in reexamining the educational process through which scientist-practitioners are prepared for their careers. As the only way to prepare people for the practice of psychology, however, the Boulder model has serious limitations, and these began to show in the 1960s.

\section{Professional Phase}

Situated as they were in academic departments, controlled as they were by researchers, the Boulder-style programs all too often neglected training for practice. Worse than neglect, practice was often demeaned. I remember sitting in a room at the University of Illinois while a student defended his dissertation before the six members of his committee, all researchers of some note and all very stern about the rigors of scientific methodology. The student had attempted a group factorial study of treatment outcome. Troubles mounted as the experiment ran its course. Clinical subjects dropped out; uncontrollable influences crept in. During the exam, the members of the committee, one after the other, tore the study into bloody ribbons. The student was devastated. He did not know what to say except to promise never to do any research again. After he left the room at the end of the session, the committee members clucked solemnly about the faults in the investigation. I did not dispute their objections to the study as a scientific experiment, but I tried to defend the student on two grounds. One was that clinical research was more difficult than running rats in $\mathrm{T}$ mazes. This remark did not endear me to the people on the committee who were running rats in $\mathrm{T}$ mazes. I also tried to defend the student by saying that I had supervised some of his practicum work and found him to be a very competent clinician. I said that he knew what he was doing - that he was dedicated, responsible, and effective. I said that if any of my loved ones got into psychological trouble, I would feel very comfortable sending them to this person for help. I met a stony silence. Nobody else in the room thought it mattered much for any of our graduates to be a good clinician. Certainly none of the others considered professional expertise sufficient qualification for a $\mathrm{PhD}$. At the end of the session, one of the committee members said, "We've wasted our time on another hand-holder."

From my experience in the Illinois Psychology Department and as a consultant to the Illinois Department of Mental Health (see the description of Elba State Hospital in my 1968 book, The Clinical Study of Social Behavior), I became convinced that we could do much better than we were doing to educate practitioners, and I felt that it was my responsibility as director of clinical training to do so. By then, Thorndike (1955) had shown that the interests of psychologists in the kinds of activities that occupy clinicians were bimodally distributed. Levy (1962), along with Kelly and Goldberg (1959), had shown 
that the modal number of publications by clinical psychologists was zero, for all the training in research and all the preaching about science students received in graduate school. From several quarters, but mainly from those who were developing behavioral approaches to clinical problems, a reasonably coherent conception of human functioning and some demonstrably effective procedures for assessment and change had come into view (Peterson, 1968). Technically, I thought we were ready to form an outright profession. Morally, I felt we were obliged to do so.

Every year I signed a contract with NIMH for our training grant. I had done some fairly careful evaluations of our own program, and it bothered me to report that we were graduating fewer than seven students per year and that $85 \%$ of those were going into academic positions. An impressive number of the people who came through the Illinois clinical program in those times are now distinguished leaders in the scientist-practitioner community. I am proud to have been part of their education. But I could not believe that the taxpayers of the state of Illinois and the United States of America were paying me to educate college professors.

I would never have had the courage to act on my convictions, however, without the support of others. At a national level, this support came from the APA Committee on the Scientific and Professional Aims of Psychology (1967), usually called the Clark Committee, after its chairman, Kenneth E. Clark. Locally, inspiration and active leadership, as well as support, came from my friend and colleague, Lloyd Humphreys, who was then head of the Psychology Department at Illinois and was also a member of the Clark Committee. The Clark Committee embodied an uncommon concentration of talent and experience. Jerome Bruner, Kenneth Spence, Paul Meehl, Carl Rogers, and others of their stature were in the group. When people of this distinction, following deliberation every six weeks for a year and a half, proposed a twotrack, practice-research, PsyD-PhD educational system, I did not see how others in our field could ignore their recommendation, and I did not feel that my own sentiments were entirely misplaced.

On a national scale, however, the ideas proposed by the Clark Committee did not get far. The concept of outright professional education was considered but voted down in Minnesota, debated but defeated in Tennessee, and noted but ridiculed in Michigan. Lloyd Humphreys carried the idea forward nationally, and he and I brought the idea before our colleagues at the University of Illinois as a specific program proposal. For several weeks the halls were noisy with discussion. The Chicago Conference on the Professional Preparation of Clinical Psychologists (Hoch, Ross, \& Winder, 1966) took place soon afterward. Humphreys and I presented our version of the Clark Committee proposal there. The idea was basically repudiated by the conference at large, but the participants gave us tacit approval to attempt our experiment at Illinois, so we went back and did it.

All through this time, another kind of ferment was bubbling away in California. The need for competent practitioners there was pressing, and all of the California universities combined were producing fewer than 20 clinical psychologists per year. Catalogue descriptions and admission policies made clear that the programs were designed to educate researchers rather than practitioners. Appeals by representatives of the California Psychological Association asking universities to expand their clinical programs went unheeded. In my view, it was this failure of the universities to respond to the challenge of education for practice that set the stage for creation of the freestanding California School of Professional Psychology and led ultimately to the professional school movement.

The public need for competent practitioners was urgent. The pressure exerted by well-qualified students to enter careers in professional psychology was intense, but the flow of admissions was choked to a trickle by the universities. In the community of practitioners, wouldbe educators lay waiting to form their own schools if the universities failed to meet the demand. Although there were scattered antecedents, establishment of the PsyD program at the University of Illinois and of the California School of Professional Psychology marked the beginning of the third phase, the professional phase, in the development of education for the practice of psychology.

After nearly 25 years, the institution of direct professional education in psychology is firmly established. The National Council of Schools of Professional Psychology (NCSPP) now includes 35 member organizations; 16 are in universities and 19 are in free-standing professional schools. A total of 7 , all but 1 in free-standing schools and all but 1 in California, award the PhD degree; 28 award the PsyD degree. The "professional school movement," as it is sometimes called, will not stop, although it appears to be slowing down. The schools were formed to meet community needs that were not met by traditional programs. The leaders are devoted to their mission, well organized, politically influential, and legally empowered to continue their operations. The professional schools will not go away, however wistfully academicians may pine for the good old days of scientific purity. The challenge before us now is to educate people for the practice of psychology in the best possible way.

\section{Relation of Science and Practice in the Education of Professional Psychologists}

Suppose we abandon the illusion that most graduates of doctoral programs in psychology will become productive researchers. Suppose we accept the fact that the interests of many people entering the field lie in practice rather than research and that many will enter jobs that impose high demands for competent professional service but offer little opportunity for research. How can we educate those people in the most effective way?

Detailed answers to that question are forthcoming through the continuing conferences and reports of NCSPP (Bourg et al., 1987; Callan, Peterson, \& Stricker, 1986; Peterson et al., in press) as well as the activities of the Joint Council on Professional Education in Psychology 
Figure 1

Professional Activity as Applied Science

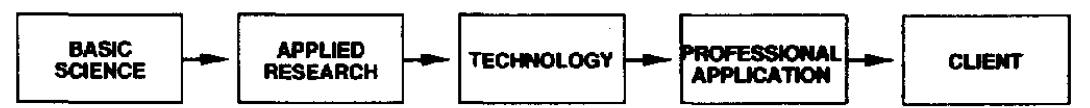

(JCPEP; 1990). Fundamental to all of these statements is the premise that "education and training for practice is grounded in the evolving knowledge base derived from the scientific discipline of psychology" (JCPEP, 1990, $p$. 3 ). Views of the relations between research and practice, however, have themselves changed as our discipline has evolved.

During the preprofessional phase of our development, the linkage of science and practice was assumed to be fairly direct. As shown in Figure 1, the first task was the establishment of basic psychological science. Once the laws of psychological nature were known, applied'research could produce the technology required for effective professional service. In this scheme, temporal priority, generality, and social value are all ordered from left to right. Attempting professional application before the necessary research was done and the laws of nature were understood was considered dangerous. The value of universal scientific principles, as soon as anybody came up with them, would clearly exceed that of applied research, and the contributions of applied researchers in providing techniques for solving classes of problems would outweigh those of professionals, who would merely apply the techniques to individual cases-although some credit might be given to professionals for artistic skill in using the procedures that science had provided.

Movement into the scientist-practitioner phase required bolder assumptions. Armed with our tests, assured by evidently successful records in treating stress casualities and selecting airplane pilots and spies in World War II, and committed to work and do no harm within the medical culture, we were prepared to offer our professional services, such as they were, to an otherwise underserved public, as long as we also devoted our special energies to the pursuits of systematic research. A reciprocal relationship between science and practice, as represented in Figure 2, was assumed. It was never assumed that research and professional service were of equal importance. Our science-profession was still dedicated fundamentally to advancing knowledge and improving technology. Once the right research was done, professional applications would follow more or less routinely.

Even in the applications, however, it was considered important to "think scientifically." Even if practitioners rarely produced research, the argument went, they needed to "know how to think" in their approach to professional problems. So students were trained to do theory-driven, verificational research within a positivist philosophy of science carried over from the preprofessional phase of our development. All of the emphasis on experimental design and quantitative methods, all of the insistence on involvement in research throughout graduate study, and all of the importance assigned to the dissertation in traditional research programs were presumably essential not only in preparing students for careers of productive scholarship, but in teaching them to "think like psychologists" in professional practice.

Since the early days, important changes have come about in the more liberal scientist-practitioner programs. Training for practice is not neglected to the degree it was before the professional schools came along. Neopositivist philosophies are being replaced by less restrictive epistemologies. A gradual broadening of the scope of defensible inquiry has been underway at least since the time of the Chicago Conference. The elaboration of single case and time-series methodologies and of quasi-experimental designs has allowed scientist-practitioners to examine issues of greater practical importance than they could consider when the demands for close experimental control of confounding influences forced them into laboratories. Yet a recent survey of the statistical and methodological curricula in American and Canadian PhD programs still shows a heavy emphasis on training for traditional laboratory research, a neglect of newer, often more useful procedures, and no evidence that the methodological curricula have advanced much in the past 20 years (Aiken et al., 1990).

This condition is unfortunate in the education of scientists and scientist-practitioners. In the education of practitioners, it is pernicious, for it offers the illusion of training in rigorous thought but not the genuinely useful training in strategies of inquiry that effective practice demands. Science and practice differ in fundamental ways. Science begins and ends in a body of systematic knowledge. Basic research begins with a conception, which guides investigation, whose results either refute or sustain a proposition derived from the conception. Even applied research is focused on the discipline, although the con-

\section{Figure 2}

Science and Practice as Reciprocally Related

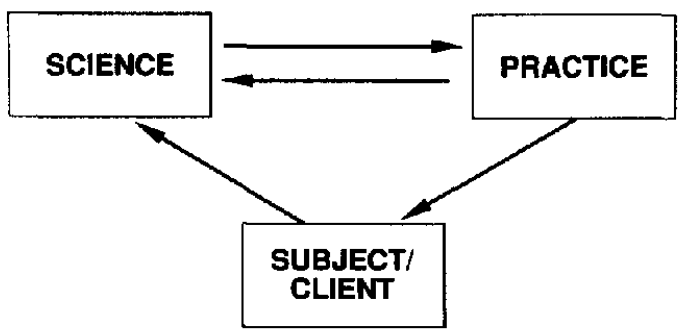


tributions are usually technological rather than theoretical; a more accurate test, a more effective method of treatment. Scientists are free to choose the issues they examine. In the interest of precision they limit the scope of inquiry and control extraneous influences. Type 1 errors, in which natural effects are falsely claimed, are scrupulously avoided to keep from misleading other investigators and the lay public, and to avoid damaging the credibility of the scientific enterprise and the individual scientist when the falsity of the claim is revealed in later investigations. Type 2 errors, in which effects that actually occur in nature are denied or neglected, do not matter so much. Science moves at its own deliberate pace. Each new finding is integrated with those that have come before, and each body of research is consolidated before entry into the next area is attempted. Between rare discontinuities, the scientific view of nature is gradually illuminated as the process of discovery unfolds.

Professional activity begins and ends in the condition of the client. Whether the client is an individual, a group, or an organization, the responsibility of the practitioner is to help improve the client's functional effectiveness. The practitioner does not choose the issue to examine; the client does. The simplifications and controls that are essential to science cannot be imposed in practice. Each problem must be addressed as it occurs in nature, as an open, living process in all its complexity, often in a political context that requires certain forms of action and prohibits others. All functionally important influences on the process under study must be considered. A scientist examining cognitive activity in psychotherapy may control biological and social influences by subject selection or other means. A clinician attempting rational-emotive psychotherapy with a patient who is drinking 16 ounces of hard liquor every night must include the physiological and interpersonal effects of alcohol abuse in any useful formulation of the problem and in any useful program for its treatment. At its best, practice runs ahead of research. Each case is unique. The pattern of conditions the client presents has never occurred in exactly this form before, and the most beneficial pattern of professional action cannot rest only on scientifically established procedures, although any contingencies established in prior research must not be ignored. The measure of effect goes beyond statistical significance to functional importance. It is not enough to determine whether a difference is random or replicable. The difference has to matter to the client. Insofar as the logic of statistical analysis applies to professional action, errors of the second kind are just as damaging as errors of the first kind. To ignore a condition that truly affects the process under study can literally be fatal.

The process of inquiry in disciplined practice is represented in Figure 3. The needs of the client, not the need for general knowledge, drive the study. Instead of starting with science and applying what we know for sure, we staft with the client and apply all the useful knowledge we can find. If some of the knowledge is qualitative or "humanistic," we work within it not because we are muddle-headed or tender-minded, but because that is the form of knowledge that provides the best understanding of the client. The first step in disciplined inquiry is assessment, whose intricacies I cannot even summarize here but whose most useful form consists essentially of a close study of the functional processes involved in the case at hand by multiple methods, in natural settings, over time (cf. Peterson, 1968; Peterson \& Fishman, 1987). The assessment is guided by a conception of the process under study, which includes a theoretical identification of the aspects of functional process that need to be examined, as well as the epistemological assumptions and axiological values that underlie the theory. The assessment is also influenced by the prior experience and knowledge of the examiner. This includes any empirical research that per-

\section{Figure 3}

Professional Activity as Disciplined Inquiry

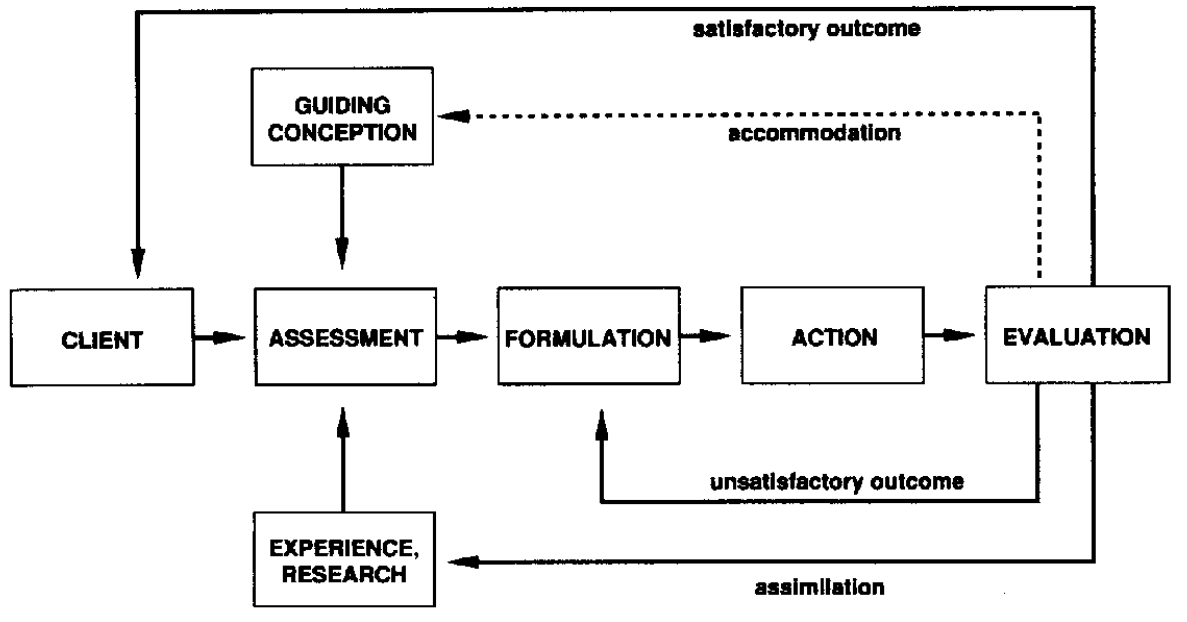


tains to the class of conditions represented by the client, but also includes remembered examples of similar cases in the previous experience of the practitioner. From the assessment, a formulation of the particular case is developed-that is, the best understanding that the examiner can construct.

The issue that the client initially presented is typically reframed at this stage. The formulation implies some form of action, either an intervention that offers the best available prospect of benefit to the client or a decision that will be useful to the client. The effects of action are then evaluated. If client and examiner agree that the decisions they have reached or the changes they have accomplished suffice for the client, the inquiry is concluded. If either client or examiner consider the outcomes insufficient, further cycles of reformulation, action, and evaluation may continue until an acceptable outcome is reached. Acceptable outcomes may include the decision by either or both parties that the attentions of the practitioner are of no use to the client.

Each case the practitioner studies adds to the store of knowledge he or she can bring to the next case. Usually the experience is assimilated within the body of comparable experiences the practitioner has accumulated previously. Occasionally, however, the outcomes or other characteristics of a case are so sharply inconsistent with the guiding conception the practitioner has followed until that time that an accommodating change in the conception is required.

If the inquiry, or a run of inquiries, has been conducted in a sufficiently systematic way to allow generalization of findings, contributions to research or theory may result. In professional situations, however, the interests of the client prevail over all other interests, and this usually means that data cannot be collected in a way that satisfies the demand for rigorous scientific analysis. Decisions are informed by sufficient approximation. Interventions are delivered in confounded packages for maximum immediate effect. The idea that every client can be a subject and every practitioner a scientist is a noble aspiration, but for the most part it is also a romantic fantasy.

Question: How can we teach students to conduct inquiries of the kinds that are needed in practice? Answer: By requiring them to conduct inquiries over the range of settings and client conditions that they are likely to encounter in practice, under close supervision in which the support required for confident professional action is provided but in which the formulations and actions of the trainee are systematically subjected to critical review. The educational policy that governs the curriculum in practitioner programs is that students need to learn to do what they will be doing throughout their professional careers, not what their professors are doing nor what the professors think the students ought to be doing. The belief that training in traditional experimental design and quantitative method will transfer to the world of practice violates one of the few principles of learning that psychologists have established, namely that generalization of performance skills from one situation to another depends on the similarity of stimulus conditions across situations. Students need to learn the skills of practice by practicing in the settings they will encounter as professionals.

Nearly all practitioner programs include a dissertation requirement. Conduct of dissertation-type research is not conceived as the primary aim of training, but as a natural product of the kind of critical analysis in which the student is engaged throughout graduate study and will continue throughout his or her professional career. Instead of defining "scientific method" beforehand and requiring students to select a problem that suits the method, problems are chosen because they are found to be important in practice, and methods are molded to suit the problem. The only constraints are that the issue has to be professionally significant and the inquiry has to meet stringent standards of scholarship. The topics that are studied under these conditions and the methods that are used in examining them are quite different from those that are seen in scientist-practitioner programs.

Ducker (1980) surveyed dissertation policies and practices in the 144 APA-approved programs in clinical counseling and school psychology listed in the American Psychologist for 1979. At that time, only 6 of the programs were designed to educate practitioners, so the sample is made up almost entirely of scientist-practitioner programs. Among the 74 respondents who returned surveys, $66 \%$ claimed that they had no specific policies limiting the types of designs appropriate for dissertations. When asked what designs were actually used in dissertation research, however, $41 \%$ mentioned laboratory experiments and 22\% mentioned field experiments. Descriptive studies, phenomenological analyses, and case studies were mentioned by $1.3 \%$, that is, only 1 of the 74 respondents.

No comparable study of dissertations in practitioner programs has been done, but a description of PsyD dissertations by Rutgers students offers a demonstration of the kinds of investigations that are undertaken when practical significance drives the project and methods of inquiry are chosen to suit each problem. Over the three academic years ending in 1987, 1988, and 1989, 73 dissertations were completed by students in the Rutgers practitioner programs. Of these, the most common studies, $41 \%$, were needs analyses and descriptions of available professional services. When students asked what they needed to know most in order to practice effectively, the questions that arose most often were, "What are the needs in the community, and what kinds of services are offered to meet these needs?" Studies included a nationwide survey of programs for gifted children, a nationwide survey of mental health services for black students in predominantly white colleges, and several investigations in which experienced professionals were interviewed to find out how they handled situations that the students had encountered but about which no useful information, scientific or otherwise, could be found in the literature. A study of clinicians who had extensive experience working with lower income urban Hispanic clients and a study of clinicians who became pregnant while they were doing 
psychoanalytic therapy (to see how they handled transference and related issues) offer examples. Several followup studies of participants in established service programs were also undertaken.

Next most common were projects in which the student-practitioner designed, implemented, and evaluated a service project of some kind, or tried to. Twenty-seven percent of the studies were of this kind. The range of programs and settings was extensive: educational programs of many kinds, prerelease and probational programs in corrections, training programs in corporate settings, data management systems in public agencies, and a wide range of clinical programs with various clinical populations. Many of the investigations were carried through to a successful conclusion, but a considerable number bogged down because key administrators moved, political climates changed, or some other condition prevented completion of the project. In those cases, reports of the initial plan and subsequent experience were merely added to the lore on which practice so often is based.

Seven dissertations were concerned with the psychometric properties of assessment procedures, five were diagnostic studies of specified clinical populations, five were replicated case studies, and five were conceptual analyses, nonempirical "think pieces" in which the student examined the literature on an issue of professional importance and developed his or her own conception of the topic. In the years from 1987 to 1989 , only one student elected to do a laboratory experiment.

Data-gathering procedures included survey questionnaires (most common), interviews (next most common), performance records and direct observations, standardized tests, new unstandardized tests, and narrative accounts, both written and oral. Students typically had to design their own survey procedures and then develop inductive coding systems to aid in interpreting the data. The context of discovery prevailed much more often than the context of verification. Such strategies as grounded theory (Glaser \& Strauss, 1967) were often used to make sense of narrative information in new areas of investigation.

Data were typically examined both qualitatively and quantitatively. Sophisticated statistical analyses were only occasionally justified or required. The most common statistical procedures were frequency comparisons and other nonparametric methods, simple correlation, $t$ tests, and simple analyses of variance. In some cases more complex methods, such as factor analysis and multiple regression analyses, were useful. The rudimentary course in quantitative methods that is required of all students in the Rutgers PsyD programs provided both necessary and sufficient preparation for most of the studies. Where more sophisticated procedures were needed, the students had no trouble learning them or finding expert assistance.

Scholarship was appraised not by applying inappropriate standards of scientific research but by raising the questions appropriate to competent professional inquiry. Does the method suit the problem? Is a thorough understanding of pertinent literature shown in the report? Is the account conceptually coherent? Is it free of internal contradiction? Is it accurate, that is, consistent with known empirical facts? Are the limits of the study appreciated and clearly stated? Is the presentation articulate and rhetorically persuasive?

A few of the dissertations are of general interest in their own right. A model program for developmentally disabled children and a descriptive study of the life histories of elderly black women, for example, carry a significance beyond the local needs that inspired them. Others may be useful as exploratory studies. They raised as many questions as they answered and fairly cried out for more thorough, controlled research on the issues they brought to light. Most of them, however, are useful only in reference to the particular problems they were designed to address. They do not replace $\mathrm{PhD}$ dissertations. They certainly are no substitute for long-term programmatic research on topics of general importance. In requiring PsyD dissertations, we ask students to demonstrate mastery of systematic strategies of inquiry appropriate to the problems that they encounter in professional work. That is what they do, and that is all most of them do.

Any practitioner who expects to serve the needs of a human community has to realize that those needs are wide ranging. Biological, psychological, interpersonal, and organizational processes are all involved in human functioning. None can be neglected in the education of professional psychologists. The curriculum must be comprehensive. Just what to teach over the wide biopsychosocial range allows some variation. Stuffing students' heads with a complete encyclopedia of empirical facts is impossible and would be useless anyway because most of the issues that preoccupy researchers are irrelevant to practice. Trying to teach all currently available techniques is equally impossible and would be unwise in any case because today's techniques are bound to be replaced by better ones if researchers do their work effectively. What doctoral professionals need on entry into the world of practice is (a) a guiding conception of human function that incorporates all of the aforementioned levels within a life-span developmental perspective, (b) those substantive facts that are decisively important in understanding the functional processes involved, (c) disciplined strategies of inquiry and change that provide a systematic approach not only to familiar problems but novel situations as well, (d) a repertoire of techniques for assessment and change at the individual, group, and organizational levels, (e) an eagerness to learn new conceptions and methods as these become available, and (f) the analytical skills, more philosophical than scientific, that are required to identify useful conceptions and sound practices.

\section{Epilogue}

A science-based profession can be formed in either of two ways. Practice can be restricted to fit the science, or the science can be developed to fit the practice. The former course is implicit in the concept of professional activity as applied science that was commonly assumed in the 
early history of psychology and is sometimes proposed by leaders in our field today. In all of human civilization, however, no profession has ever grown that way. Road builders did not wait for highway engineering to produce a developed technology before they cleared trails, packed down dirt, and added cobblestones, then gravel, and finally asphalt and concrete to provide efficient surfaces for wheeled vehicles. When they needed to go from one place to another, they got there the best way they could. Medical practice has been closely linked with scientific knowledge for less than 200 years, but physicians were doing their best to heal the sick for thousands of years before. The best thing scientists in psychology can do to improve practice is not to deride their professional colleagues for going beyond tested knowledge but to extend the base of disciplined knowledge and improve the procedures that professionals need to meet the demands of public service.

Basic research, applied research, and professional work are all required, although it is absurd to expect the same people to do them all. We are likely to serve the public most effectively and to advance most rapidly as a discipline if basic scientists, applied scientists, and professionals work toward their separate goals in cooperative and complementary ways. When I reviewed the history of professional education in psychology at the beginning of this article, I spoke of preprofessional, scientistprofessional, and professional "phases" of development, not "stages" in which each period replaces the one before. Direct education for the practice of psychology has not replaced the education of scientist-practitioners, any more than the education of scientist-practitioners replaced the education of basic scientists. The metaphor of an increasingly complex tonal wave and the image of a string quartet come to mind. When the viola and the cello join the violins, the violins do not stop playing. All blend together in a rich harmony. If dissonance is heard, it is not useful for the performers to smash the instruments of their fellow artists. If the cellist hears the viola going flat, a gentle comment to the partner is in order. But the best thing all of them can do is tune their own instruments.

\section{REFERENCES}

Aiken, L. S., West, S. G., Sechrest, L., Reno, R. R., Roediger, H. L., Scarr, S., Kazdin, A. E., \& Sherman, S. T. (1990). Graduate training in statistics, methodology, and measurement in psychology: A survey of PhD programs in North America. American Psychologist, 45, 721734.

American Psychological Association, Committee on Scientific and Professional Aims of Pychology. (1967). The scientific and professional aims of psychology. American Psychologist, 22, 49-76.

American Psychological Association, Committee on Training in Clinical Psychology. (1947). Recommended graduate training programs in clinical psychology. American Psychologist, 2, 539-558.

Barlow, D. H., Hayes, S. C., \& Nelson, R. O. (1984). The scientistpractitioner: Research and accountability in clinical and educational settings. New York: Pergamon.

Bourg, E. F., Bent, R. J., Callan, J. E., Jones, N. F., McHolland, J., \& Stricker, G. (1987). Standards and evaluation in the education and training of professional psychologists. Norman, OK: Transcript Press.

Callan, J. E., Peterson, D. R., \& Stricker, G. (1986). Quality in professional psychology training: A national conference and self-study. Norman, OK: Transcript Press.

Ducker, D. (1980, September). Survey of dissertations in clinical and professional psychology programs. Paper presented at the 88th Annual Convention of the American Psychological Association, Montreal.

Glaser, B., \& Strauss, A. (1967). The discovery of grounded theory. New York: Aldine.

Hoch, E. L., Ross, A. O., \& Winder, C. L. (Eds.). (1966). Professional preparation of clinical psychologists. Washington, DC: American Psychological Association.

Joint Council on Professional Education in Psychology. (1990, August). In T. T. Stigall, (Chair), Report. Symposium conducted at the 98th Annual Convention of American Psychological Association, Boston.

Kelly, E. L., \& Goldberg, L. R. (1959). Correlates of later performance and specialization in psychology: A follow-up study of trainees assessed in the VA Selection Research Project. Psychological Monographs, 73 (12, Whole No. 482).

Levy, L. H. (1962). The skew in clinical psychology. American Psychologist, 17, 244-249.

Peterson, D. R. (1968). The clinical study of social behavior. New York: Appleton-Century-Crofts.

Peterson, D. R., \& Fishman, D. B. (Eds.). (1987). Assessment for decision. New Brunswick, NJ: Rutgers University Press.

Peterson, R. L., McHolland, J., Bent, R. J., Davis-Russell, E., Edwall, G. E., Magidson, E., Polite, K., Singer, D. L., \& Stricker, G. (Eds.). (in press.) The core curriculum in professional psychology. Washington, DC: American Psychological Association.

Raimy, V. C. (1950). Training in clinical psychology. Englewood Cliffs, NJ: Prentice-Hall.

Stricker, G., \& Keisner, R. H. (Eds.). (1985). From research to clinical practice: The implications of social and developmental research for psychotherapy. New York: Plenum.

Thorndike, R. L. (1955). The structure of preferences for psychological activities among psychologists. American Psychologist, 10, 205-207. 